\title{
Treating in-stent restenosis with drug-eluting balloon with intracoronary ultrasound control, with later optical coherent tomography control
}

Zastosowanie balonu pokrytego lekiem pod kontrolą ultrasonografii wewnątrzwieńcowej w leczeniu restenozy w stencie, z odległą kontrolą przy użyciu optycznej tomografii koherentnej

\author{
Andrzej Szczepański ${ }^{1}$, Janusz Sławinn', Piotr Kübler, ${ }^{1,2}$, Ewa A. Jankowska ${ }^{1,2}$, Waldemar Banasiak ${ }^{1}$, Piotr Ponikowski ${ }^{1,2}$, \\ Krzysztof Reczuch ${ }^{1,2}$
}

1Klinika Kardiologii, 4 Wojskowy Szpital Kliniczny, Wrocław

${ }^{2}$ Klinika Chorób Serca, Akademia Medyczna, Wrocław

Post Kardiol Interw 2010; 6, 4 (22): 203-207

DOI: $10.5114 /$ pwki.2010.17635

\begin{abstract}
We present a case report on treating drug eluting stent restenosis with a drug-eluting balloon. In order to recognise the cause of restenosis and to ensure better control of $\mathrm{PCl}$ we used intracoronary ultrasound. After three months we confirmed the positive effect of the earlier procedure in the coronary angiography and optical coherent tomography. We discuss the advantages of additional metods of coronary examination and the benefits of using the new device designed for the treatment of in-stent restenosis.
\end{abstract}

Key words: restenosis, drug eluting balloon, intracoronary ultrasound, optical coherent tomography

Streszczenie

Przedstawiamy opis zabiegu przeznaczyniowej angioplastyki wieńcowej z powodu restenozy we wcześniej implantowanym stencie DES z zastosowaniem balonu pokrytego lekiem. W celu właściwego rozpoznania przyczyn restenozy oraz kontroli PCI zastosowano ultrasonografię wewnątrzwieńcową. Po 3 miesiącach potwierdzono dobry efekt wcześniejszej procedury w kontrolnej koronarografii oraz za pomocą optycznej tomografii koherentnej. W omówieniu podano korzyści z zastosowania dodatkowych metod obrazowania oraz nowego urządzenia przeznaczonego do leczenia restenozy.

Słowa kluczowe: restenoza, balon pokryty lekiem, ultrasonografia wewnątrzwieńcowa, optyczna tomografia koherentna

\section{Wprowadzenie}

Pomimo dynamicznego rozwoju kardiologii interwencyjnej ograniczenie zjawiska restenozy w stencie (ang. instent restenosis, ISR) pozostaje głównym wyzwaniem w przypadku zabiegów angioplastyki wieńcowej (ang. percutaneus coronary intervention, $\mathrm{PCl}$ ). Wprowadzenie stentów uwalniających leki (ang. drug eluting stent, DES) wyraźnie zmniejszyło jej częstość [1, 2]. Niestety zabiegi $\mathrm{PCl}$ dotyczące zmian złożonych, długich, a szczególnie bifurkacji, wiążą się z wciąż relatywnie dużym ryzykiem restenozy oraz potrzeby ponownej rewaskularyzacji. W przypadku restenozy w DES szczególnie istotne jest roz- poznanie jej przyczyn, w czym pomocne mogą być dodatkowe metody obrazowania, takie jak ultrasonografia wewnątrzwieńcowa (ang. intra-coronary ultrasound, ICUS). Podstawowymi metodami leczenia restenozy są angioplastyka balonowa (ang. plain old balloon angioplasty, POBA) oraz implantacja DES. Pozostałe metody, takie jak brachyterapia, zastosowanie aterektomii kierunkowej lub rotacyjnej czy balonu tnącego, są zdecydowanie rzadziej stosowane z powodu swojej złożoności oraz braku udowodnionej przewagi [3-5]. W leczeniu tego typu zmian nową, interesującą opcją stały się balony pokryte lekiem (ang. drug eluting baloon, DEB).

Adres do korespondencji/Corresponding author:

lek. Andrzej Szczepański, Klinika Kardiologii, 4 Wojskowy Szpital Kliniczny, ul. Rudolfa Weigla 5, 50-981 Wrocław, tel.: +48 717660373 ,

e-mail: anski@mp.pl

Praca wpłynęła 28.06.2010, wersja poprawiona 11.10.2010, przyjęta do druku 20.10.2010. 


\section{Opis przypadku}

Mężczyzna 53-letni, po zabiegu pomostowania aortalno-wieńcowego (ang. coronary artery bypass graft, CABG), angioplastyce pnia lewej tętnicy wieńcowej z implantacją DES, z nadciśnieniem tętniczym oraz hipercholesterolemią, został przyjęty do kliniki z powodu nawrotu dolegliwości dławicowych w III klasie czynnościowej wg CCS. Pięć miesięcy wcześniej chory przebył zabieg PCl z implantacją DES uwalniającego zotarolimus $(3,5 \times 18 \mathrm{~mm})$ do dystalnego odcinka pnia lewej tętnicy wieńcowej i ujścia gałęzi okalającej. Zabieg wykonano z powodu stwierdzenia ciasnego zwężenia w dystalnym odcinku pnia lewej tętnicy wieńcowej, braku napływu do gałęzi okalającej z przęsła, przy zachowanym prawidłowym napływie do LAD z przęsła tętniczego.

Przy przyjęciu w badaniu fizykalnym nie stwierdzono istotnych odchyleń od stanu prawidłowego, ciśnienie tętnicze 115/80 mm Hg. W EKG zarejestrowano normogram, rytm miarowy, zatokowy 60/min, płytko ujemne załamki T w $V_{1}-V_{3}$. W badaniach laboratoryjnych wykonanych przy przyjęciu nie odnotowano istotnych odchyleń od stanu prawidłowego, troponina I w granicach normy, cholesterol całkowity 156 mg\%, cholesterol frakcji LDL 80 mg\%.

W kontrolnym badaniu koronarograficznym wykonanym po 5 miesiącach stwierdzono istotną angiograficznie restenozę $w$ dystalnym odcinku pnia lewej tętnicy wieńcowej, o charakterze ogniskowym, zlokalizowaną w środ-

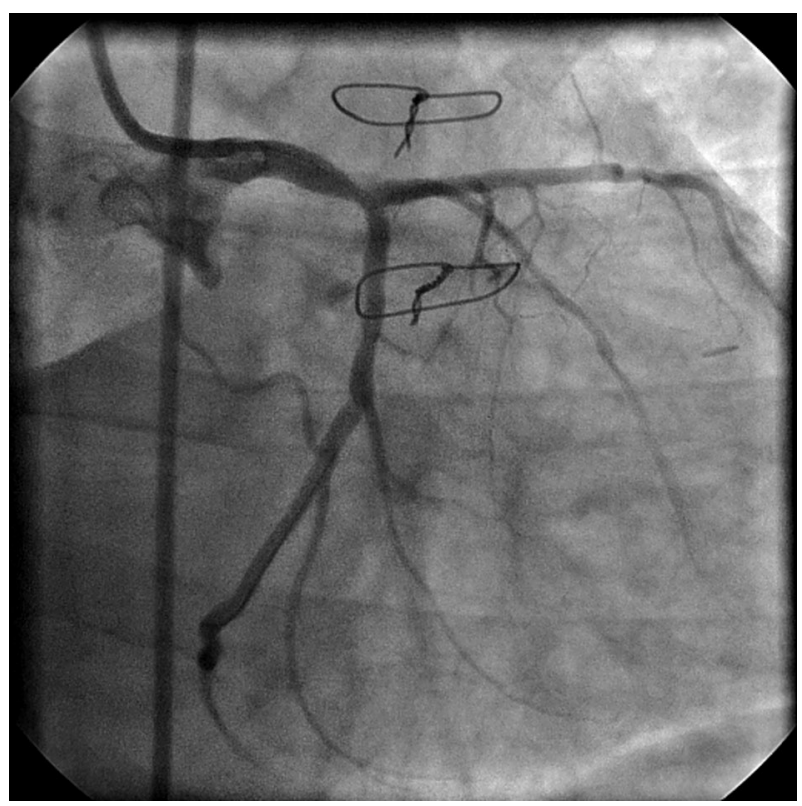

Ryc. 1. RAO 17 CAUD 20 - zwężenie w dystalnej części pnia lewej tętnicy wieńcowej - wskazanie do dalszej oceny oraz zabiegu angioplastyki przeznaczyniowej

Fig. 1. RAO 17 CAUD 20 - stenosis in distal portion of left main - indication for further assesment and angioplasty kowej części implantowanego stentu (ryc. 1.). Dodatkowo odnotowano drożne przęsło do gałęzi przedniej zstępującej i brak napływu kontrastu do gałęzi okalającej z drugiego pomostu tętniczego. W celu oceny restenozy oraz optymalizacji zabiegu PCI zastosowano ICUS, w której stwierdzono w dystalnej części pnia lewej tętnicy wieńcowej brak pełnej ekspansji wcześniej implantowanego stentu z restenozą i minimalnym polem powierzchni światła naczynia $4,1 \mathrm{~mm}^{2}$ oraz polem powierzchni stentu $7,4 \mathrm{~mm}^{2}$ (ryc. 2.). Brak pełnego rozprężenia dotyczył środkowego odcinka stentu, z dobrym rozprężeniem w odcinku proksymalnym (dystalna część LM - pomiar referencyjny, pole powierzchni światła naczynia 13,5 mm²) i dystalnym (proksymalny odcinek Cx - pomiar referencyjny, powierzchnia światła naczynia 11,1 mm²). Wykonano dwukrotnie predylatację cewnikami balonowymi odpowiednio 3,5 × $15 \mathrm{~mm}$ (24 atm) oraz 4,0 × 15 (18 atm). W kontroli ICUS zdecydowanie lepsza ekspansja stentu z minimalnym polem powierzchni światła naczynia $9,0 \mathrm{~mm}^{2}$ (ryc. 3.), bez cech dysekcji w segmencie naczynia poddanym leczeniu. Następnie cewnikiem balonowym pokrytym lekiem (paklitaksel) Braun SeQuent 4,0 × $17 \mathrm{~mm}$ wykonano 30-sekundową aplikację w miejscu zwężenia (7 atm).

Po 3 miesiącach pacjent został przyjęty celem wykonania kontrolnego badania inwazyjnego naczyń wieńcowych. W wywiadzie nie zgłaszał dolegliwości dławicowych

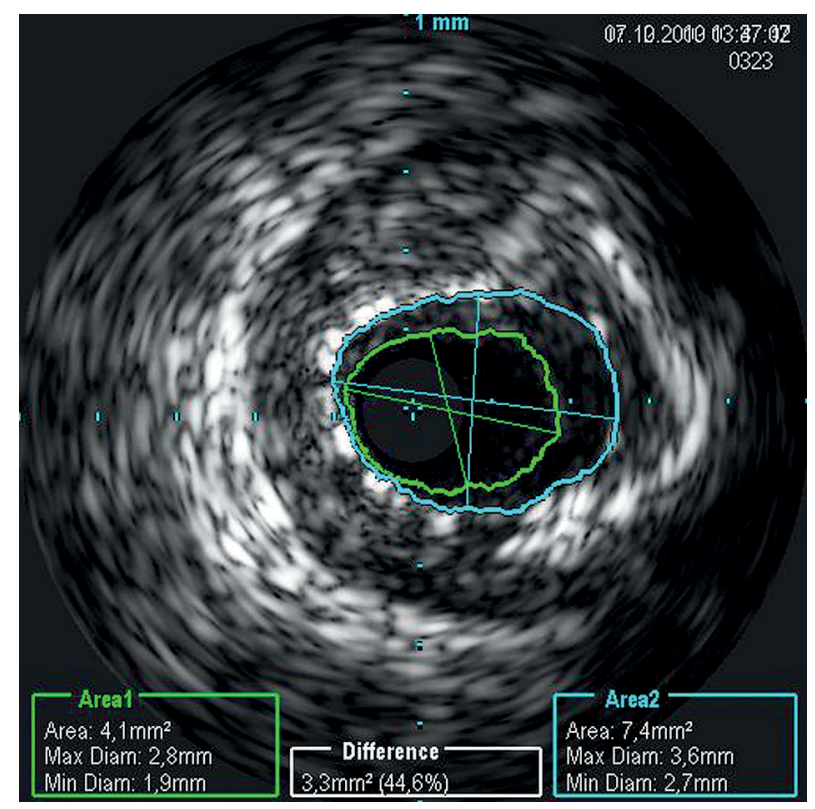

Ryc. 2. Kontrola ICUS - brak ekspansji stentu w odcinku medialnym z minimalnym polem powierzchni światła naczynia $4,1 \mathrm{~mm}^{2}$

Fig. 2. ICUS - underexpansion in medial portion of stent, minimal lumen cross section area $4.1 \mathrm{~mm}^{2}$ 


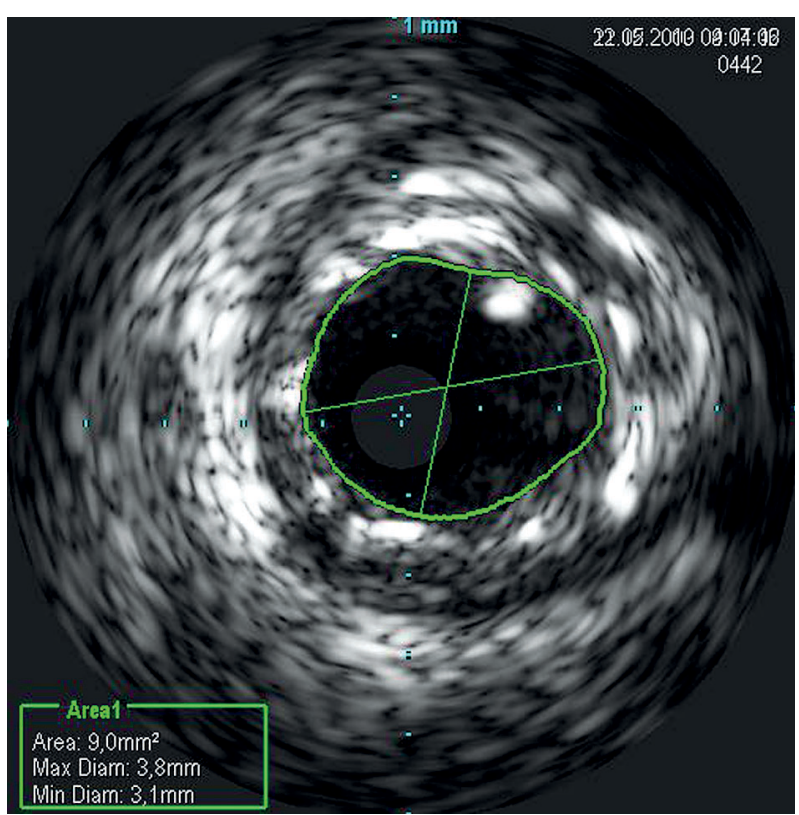

Ryc. 3. Kontrola ICUS po dwukrotnej predylatacji balonowej - pole powierzchni światła naczynia $9,0 \mathrm{~mm}^{2}$

Fig. 3. ICUS assessment post double baloon expansion - lumen cross section area $9.0 \mathrm{~mm}^{2}$

od czasu ostatniego zabiegu PCI. W badaniu fizykalnym oraz wykonanych badaniach laboratoryjnych - bez odchyleń od stanu prawidłowego. Elektrokardiogram porównywalny z wcześniejszymi. Wykonano kontrolną koronarografię z dodatkowym zastosowaniem optycznej tomografii koherentnej (ang. optical coherence tomography, OCT). W badaniu stwierdzono prawidłowy obraz angiograficzny (ryc. 4.). W OCT potwierdzono prawidłową apozycję i ekspansję stentu. Dodatkowo stwierdzono pokrycie wszystkich przęseł stentu przez homogenną warstwę śródbłonka, z charakterystycznym wysokim rozproszeniem światła oraz z zachowanym regularnym kształtem światła naczynia. Odnotowano pokrycie przęset stentu przez warstwę śródbłonka maksymalnie 0,25 mm (ryc. 5.).

\section{Omówienie}

Restenoza jest nadal jednym z głównych problemów kardiologii interwencyjnej. Spośród czynników sprzyjających wystąpieniu restenozy należy wyróżnić te związane z samym zabiegiem. Najsilniejszym czynnikiem jest mała minimalna średnica naczynia po zabiegu angioplastyki, świadcząca o niedoprężeniu stentu [6]. Dodatkowe czynniki to niepetne pokrycie zmiany pomiędzy stentami [7] oraz przemieszczenie blaszki miażdżycowej, brak pokrycia stentem segmentu naczynia uszkodzonego podczas predylatacji. W opisanym przez nas przypadku właśnie nierozpoznane podczas pierwszego zabiegu niedoprężenie stentu w jego środkowym odcinku (dystalna część pnia lewej tętnicy wieńcowej i ujście gałęzi okalającej)

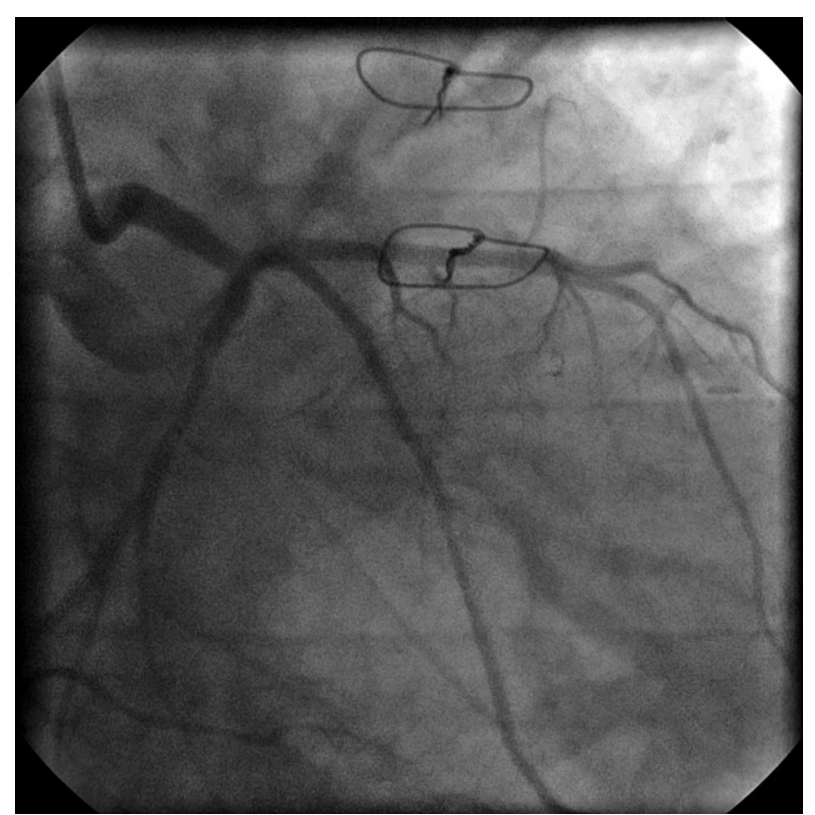

Ryc. 4. RAO 34 CAUD 21 - dobry efekt angiograficzny po 3 miesiącach od zabiegu z zastosowaniem DEB

Fig. 4. RAO 34 CAUD 21 good result in three month's follow-up angiography after angioplasty with $D E B$

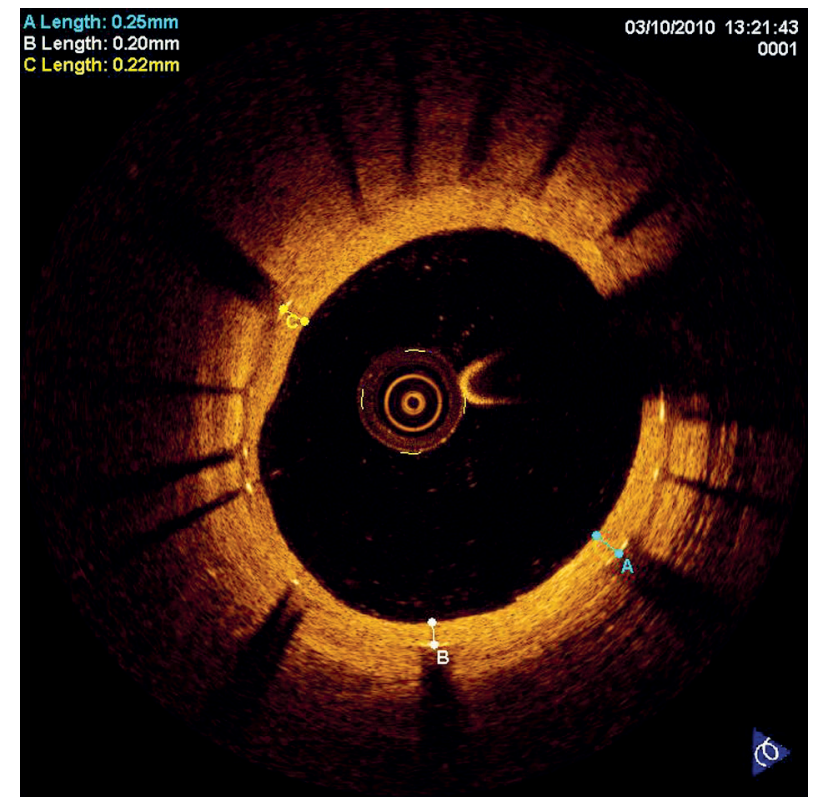

Ryc. 5. Kontrola OCT po 3 miesiącach, pokrycie przęseł stentu przez homogenną warstwę śródbłonka

Fig. 5. OCT image three monts after angioplasty with $D E B$, struts covered by homogeneous layer of endothelium

było najprawdopodobniej przyczyną niepowodzenia pomimo zastosowania DES. Należy dodać, że implantacja DES 3,5 × $18 \mathrm{~mm}$ została przeprowadzona pod ciśnieniem 
12 atm, następnie wykonano postdylatację typu kissing cewnikami balonowymi o średnicach $4,0 \mathrm{~mm}$ oraz $3,5 \mathrm{~mm}$ pod ciśnieniem w obu cewnikach 12 atm. Zastosowanie ICUS podczas drugiego zabiegu pozwoliło nie tylko na dokładną ocenę morfologiczną zmiany, ale też na trafny wybór techniki zabiegu (długość oraz średnica cewników balonowych). Nie do przecenienia była także ocena naczynia po dwukrotnej postdylatacji, dzięki której oceniono rozprężenie stentu oraz wykluczono obecność niewidocznych angiograficznie powikłań, np. brzeżnej dysekcji. Wobec mniejszej śmiertelności pacjentów poddanych zabiegom PCI na pniu lewej tętnicy wieńcowej z użyciem IVUS, stwierdzonej w pracy Parka [14], zastosowanie tej techniki podczas takich zabiegów jest postępowaniem optymalnym, a według coraz większej grupy specjalistów - koniecznością.

Biorąc pod uwagę restenozę w DES w ujściu dużej, dominującej gałęzi okalającej, zdecydowano o dodatkowym zabezpieczeniu zmiany. Podstawową metodą dotychczas stosowaną w większości pracowni w przypadku ISR jest implantacja DES. Wybrano cewnik balonowy pokryty paklitakselem. Zasadą zastosowania DEB jest pełna ekspansja restenotycznej zmiany poprzez predylatacje, często wysokociśnieniowe lub cewnikami o większej średnicy. Następnie wykonuje się inflację cewnikiem dobranym do danego segmentu naczynia (optymalnie dzięki zastosowaniu ICUS), trwającą 30 s lub więcej, w zależności od tolerancji okluzji naczynia przez pacjenta. Metoda ta została oceniona w badaniach jako bezpieczna i nie gorsza od implantacji DES $[8,9]$. Autorom nie udało się odnaleźć w dostępnej literaturze badań klinicznych dotyczących leczenia restenozy w pniu lewej tętnicy wieńcowej z zastosowaniem DEB - leczenie miato charakter eksperymentalny.

Kontrolne badanie angiograficzne uzupełniono zastosowaniem OCT. Jest to nowa metoda inwazyjnego obrazowania naczyń wieńcowych, stosowana obecnie w badaniach naukowych, oparta na ocenie odbicia fali światła podczerwonego [10]. Wymaga ona wypełnienia naczynia słupem kontrastu, aby usunąć nieprzenikliwe dla fali świetlnej elementy morfotyczne krwi, obecnie najczęściej metoda nonocclusive [11]. Pozwala na ocenę światła oraz ściany naczynia z penetracją ok. $2 \mathrm{~mm}$, ale rozdzielczością osiową 10-20 $\mu \mathrm{m}$, a więc ok. 10 razy większą od ICUS [12]. Optyczna koherentna tomografia dzięki wysokiej rozdzielczości stanowi idealne narzędzie do oceny procesu gojenia ściany naczynia po $\mathrm{PCl}$, w tym pokrycia przęseł stentu przez śródbłonek. Jest to szczególnie interesujące, gdyż udowodniono związek późnej zakrzepicy w stencie z brakiem pełnej endotelializacji protezy [15]. Czynnikami ryzyka są pokrycie stentem ujścia gałęzi bocznej, pęknięcie przylegającej niestabilnej blaszki oraz masywny prolaps blaszki na brzegach stentu [16]. Znaczenie ma sam zabieg, w tym prawidłowa apozycja, pełne pokrycie zmiany, brak dysekcji brzeżnej, ale także rodzaj zastosowanego urządzenia. Opisywane są różnice w endotelializacji stentów o odmiennej platformie, a zwłaszcza pokrytych innym polimerem i uwalnianym lekiem [17]. Zastosowanie OCT pozwolito na opisanie morfologicznych rodzajów restenozy w stencie [13] oraz dostarczyło nowych danych dotyczących gojenia się naczynia po zabiegach PCl, szczególnie z zastosowaniem DES. Mamy nadzieję, że lepsze poznanie tych procesów pozwoli nam na jeszcze skuteczniejsze leczenie.

\section{Piśmiennictwo}

1. Sawhney N, Moses J, Leon M i wsp. Treatment of left anterior descending artery disease with srolimus-eluting stents. Circulation 2004; 110: 374-379.

2. Dangas G, Ellis S, Shlofmitz R i wsp. Outcomes of paclitaxel-eluting stent implantation in patients with stenosis of the left anterior descending coronary artery. J Am Coll Cardiol 2005; 45: 1186-1192.

3. Oliver LN, Buttner PG, Hobson H, Golledge J. A meta-analysis of randomised controlled trials assessing drug-eluting stents and vascular brachytherapy in the treatment of coronary artery instent restenosis. Int J Cardiol 2008; 126: 216-223.

4. Stane G, Ellis S, O'Shaughnessy C i wsp. Paclitaxel-eluting stents vs vascular brachytherapy for in-stent restenosis within bare-metal stents: the TAXUS V ISR randomized trial. JAMA 2006; 295: 1253-1263.

5. Mauri I, Bonan R, Weiner BH i wsp. Cutting balloon angioplasty for the prevention of restenosis: results of the cutting balloon global randomized trial. Am J Cardiol 2002; 90: 1079-1083.

6. Kastrati A, Schömig A, Elezi S i wsp. Predictive factors of restenosis after coronary stent placement. J Am Coll Cardiol 1997; 30: 1428-1436.

7. Fujii K, Mintz GS, Kobayashi Y. Contribution of stent underexpansion to recurrence after sirolimus-eluting stant implantation for in-stent restenosis. Circulation 2004; 109: 1085-1088.

8. Unverdorben M, Vallbracht C, Cremers B i wsp. Paclitaxel-coated balloon catheter versus paclitaxel-coated stent for the treatment of coronary in-stent restenosis. Circulation 2009; 119: 2986-2994.

9. Scheller B, Hehrlein C, Bocksch W i wsp. Treatment of coronary in-stent restenosis with a paclitaxel-coated balloon catheter. N Engl J Med 2006; 355: 2113-2124.

10. Fujimoto JG, Schmitt JM. Principles of OCT. In: Optical coherence tomography in cardiovascular research. Regar E (red.). Informa Healthcare 2007.

11. Prati F, Cera M, Ramazzotti V i wsp. From bench to bedside - a novel technique of acquiring OCT images. Circ J 2008; 72: 839-843.

12. Prati F, Evelyn R, Mintz G i wsp. Expert review document on methodology, terminology, and clinical applications of optical coherence tomography: physical principles, methodology of image acquisition, and clinical application for assessment of coronary arteries and atherosclerosis. Eur Heart J 2010; 31: 401-415.

13. Gonzalo N, Serruys PW, Okamura T i wsp. Optical coherence tomography patterns of stent restenosis. Am Heart J 2009; 158: 284-293.

14. Park SJ, Kim YH, Park DW i wsp. Impact of intravascular ultrasound guidance on long-term mortality in stenting for unprotected left main coronary artery stenosis. Circ Cardiovasc Interv 2009; 2: 167-177.

15. Finn AV, Joner M, Nakazava G i wsp. Pathological correlates of late drug-eluting stent thrombosis: strut coverage sa a marker of endothelialization. Circulation 2007; 115: 2435-2441. 
16. Farb A, Burke AP, Kolodgie FD i wsp. Pathological mechanisms of fatal late coronary stent thrombosis in humans. Circulation 2003; 108: 1701-1706.

17. Kim JS, Jang IK, Kim i wsp. Optical coherence tomography evaluation of zotarolimus-eluting stents at 9-month follow-up: comparison with sirolimus-eluting stents. Heart 2009; 95: 19071912. 